\title{
Penalty-Free Multi-Objective Evolutionary Approach to Optimization of Anytown Water Distribution Network
}

\author{
Calvin Siew $^{1}$ - Tiku T. Tanyimboh ${ }^{1}$ • \\ Alemtsehay G. Seyoum ${ }^{1}$
}

Received: 31 August 2015/Accepted: 20 May 2016/

Published online: 3 June 2016

(C) The Author(s) 2016. This article is published with open access at Springerlink.com

\begin{abstract}
This paper describes the development and application of a new multiobjective evolutionary optimization approach for the design and upgrading of water distribution systems with multiple pumps and service reservoirs. The optimization model employs a pressure-driven analysis simulator that accounts for the minimum node pressure constraints and conservation of mass and energy. Pump scheduling, tank siting and tank design are integrated seamlessly in the optimization without introducing additional heuristic procedures. The computational solution of the optimization problem is entirely penalty-free, thanks to pressure-driven analysis and the inclusion of explicit criteria for tank depletion and replenishment. The model was applied to the Anytown network that is a benchmark optimization problem. Many new solutions were achieved that are cheaper and offer superior performance compared to previous solutions in the literature. Detailed and extensive simulations of the solutions achieved were carried out. Spatial and temporal variations in water quality were investigated by simulating the chlorine residual and disinfection by-products in addition to water age. The hydraulic requirements were satisfied; efficiency of pumps was consistently high; effective operation of the new and existing tanks was achieved; water quality was improved; and overall computational efficiency was high. The formulation is entirely generic.
\end{abstract}

Keywords Demand-driven analysis · Pressure-driven analysis · Penalty-free constrained multiobjective evolutionary optimization - Water distribution system · Optimal pump scheduling . Service reservoir design and operation

Tiku T. Tanyimboh

tiku.tanyimboh@strath.ac.uk

1 Department of Civil and Environmental Engineering, University of Strathclyde Glasgow, James Weir Building, 75 Montrose Street, Glasgow G1 1XN, UK 


\section{Introduction}

A large proportion of the optimization models for water distribution systems focus on networks consisting of pipes only. Very few published works simultaneously incorporate the sizing and operation of tanks and pumps, multiple operating conditions and demand variations which are all typical features of water distribution systems. This is mainly attributed to the significant increase in complexity which stems from the additional design variables and multiple operational constraints. In addition, accurate dynamic simulation of the system is extremely time-consuming, particularly in evolutionary optimization algorithms that operate on large populations of candidate solutions.

The Anytown network is a hypothetical system with multiple loadings and multiple storage tanks and pumps (Walski 1987). Murphy et al. (1994) applied an evolutionary algorithm to optimize the design based on single-objective optimization with constraint-violation penalties. Walters et al. (1999) solved the problem using multi-objective optimization. Dimensional weightings were required to facilitate the aggregation of the various system improvements considered. Vamvakeridou-Lyroudia et al. (2005) employed multi-objective optimization combined with fuzzy membership functions for constraint handling purposes based on aggregators that essentially are weightings. The performance is heavily dependent on the many parameters and operators introduced.

Several researchers modified the Anytown problem by incorporating other measures of hydraulic performance. Farmani et al. $(2005,2006)$ considered the resilience index (Todini 2000) and water age (Rossman 2002). Prasad and Tanyimboh (2008) investigated the statistical flow entropy (Tanyimboh and Templeman 2000; Tanyimboh et al. 2011) and resilience index. More recently Atkinson et al. (2014) maximized flow entropy and resilience index at once in an attempt to generate hybrid solutions with properties derived from the two measures. The above-mentioned extensions and other aspects such as the uncertainties associated with the nodal demands (Spiliotis and Tsakiris 2012) were not considered in this article.

Kurec and Ostfeld (2013) addressed tank sizing for a network in the literature. They employed constraint-violation tournaments, and coefficients for tank-level imbalances. Constraint handling methods in evolutionary algorithms generally employ penalties (e.g. Kougias and Theodossiou 2013) or some form of weighting to standardize different constraint violation measures. The major disadvantage of using these parameters (Dridi et al. 2008) is that there is no rigorous method to obtain their values. Users often have to find the most effective values by experimentation that is time consuming. Moreover, penalty parameters and weightings are often problem specific in that they may perform well on some problems but not so well on others. Hence the whole cycle of calibration and trial runs has to be repeated every time a different optimization problem is solved. In addition, the optimality of the solution heavily depends on these parameters.

This paper extends previous work by the authors that was concerned with the optimization of networks with pipes only (Siew and Tanyimboh 2012a; Siew et al. 2014). The development and application of a multi-objective evolutionary optimization approach for the design and rehabilitation of water distribution systems that avoids the above-mentioned difficulties is described. The minimum node-pressure constraints are addressed implicitly with pressure-driven analysis of the distribution system. Tank sizing is carried out seamlessly using pressure-driven extended-period simulation. Tank depletion over the operational cycle (typically 24 hours) is promoted explicitly, as an extra objective to improve water quality alongside the tank replenishment objective. 
Furthermore, optimal tank siting and pump scheduling are fully integrated in the optimization procedure. Upgrading of pumping stations and the operation and energy consumption costs are considered. This new formulation achieved many new solutions that are fully feasible, satisfy both pressure and other hydraulic and operational constraints, and are cheaper than the previous solutions in the literature. The solutions achieved were assessed further, in terms of the fluctuations of the water levels in the tanks, plus the temporal and spatial variations of the water quality in the distribution system. Given the context of the Anytown network that is hypothetical, the values used in the water quality simulations were selected to achieve the prescribed minimum chlorine residual throughout the distribution system.

\section{Brief Overview of Anytown Network Optimization Problem}

A brief summary of the network is presented here for completeness. The layout of the Anytown network is shown in Fig. 1a. The source is a water treatment plant located at node 40 with a fixed water level of $3.05 \mathrm{~m}$. Water is pumped from the plant into the system via three identical pumps operating in parallel. There are two existing storage tanks located at nodes 14 and 17 both with operating water levels between $68.58 \mathrm{~m}$ and $76.20 \mathrm{~m}$. The volume of water below $68.58 \mathrm{~m}$ and above $65.53 \mathrm{~m}$ is emergency storage. Other data for pipes and nodes are available in Walski (1987).

A minimum pressure of 28.12 m must be provided at all nodes for the average day flow of 24 hours duration as well as the instantaneous peak flow, i.e. 1.8 times the average day flow. There are three different critical fire flows during which water is supplied at a minimum pressure of $14.06 \mathrm{~m}$. With one pump out of service and all tanks starting at their lowest operating levels for normal storage, the emergency storage in each tank must be sufficient for a 2-hour fire and at the same time supply peakflow demands, i.e. 1.3 times the average day flow. 35 existing pipes are considered for paralleling or cleaning and lining. In addition, there are six new pipes to be sized. One or two new tanks can be added to the network. Potential tank locations can be any of the 16 available nodes which are not connected directly to an existing tank. Tanks are connected to a node by a riser of length $30.78 \mathrm{~m}$ with the diameter to be determined.

New pumping stations are not considered but an upgrade of the existing pumping station is allowed through the addition of one or two new pumps with identical characteristics to the existing ones. Given eight average-day demand factors (one each for the eight 3-hour durations in 24 hours), eight ON-OFF status control variables are used for the operation of a single pump. As such, each status control variable corresponds to a demand factor. This enables the pump scheduling to be optimized for the different demand periods.

\section{Methodology for Tank Siting and Design}

Tank siting and design are addressed seamlessly in the optimization model. With extendedperiod pressure-driven analysis, the tanks are simulated realistically. Consequently no additional constraints are needed to prevent tanks from overfilling or dropping below emergency operating levels. The reason is that the limits of the operational levels are explicitly recognised by the hydraulic simulator during the extended-period simulation as standard (Siew and 


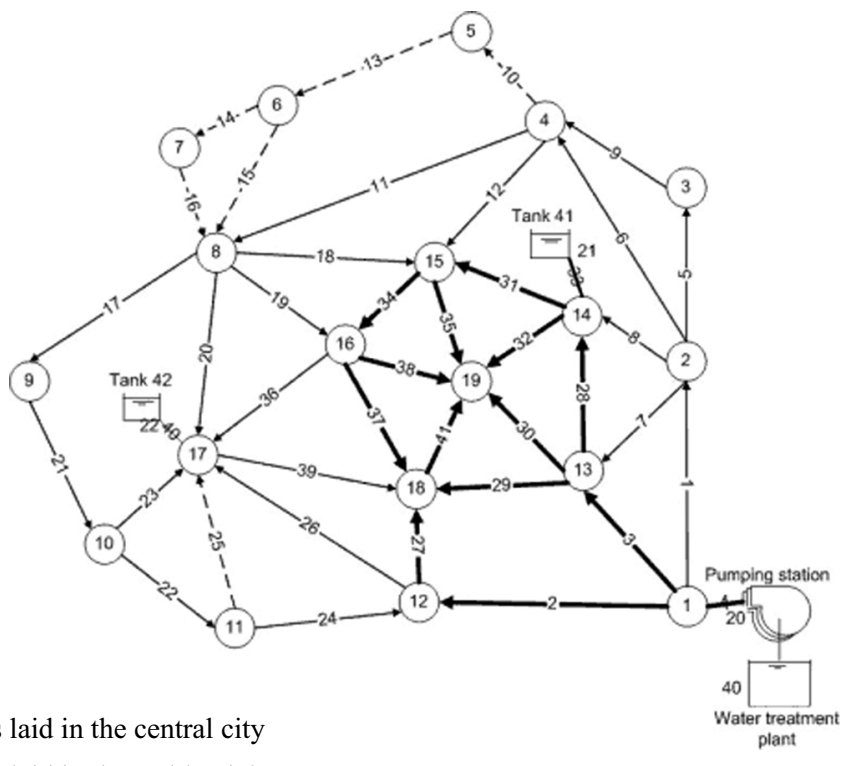

Pipes laid in the central city

ater treat
plant

Pipes laid in the residential area

New pipes

(a) Topology of the distribution system

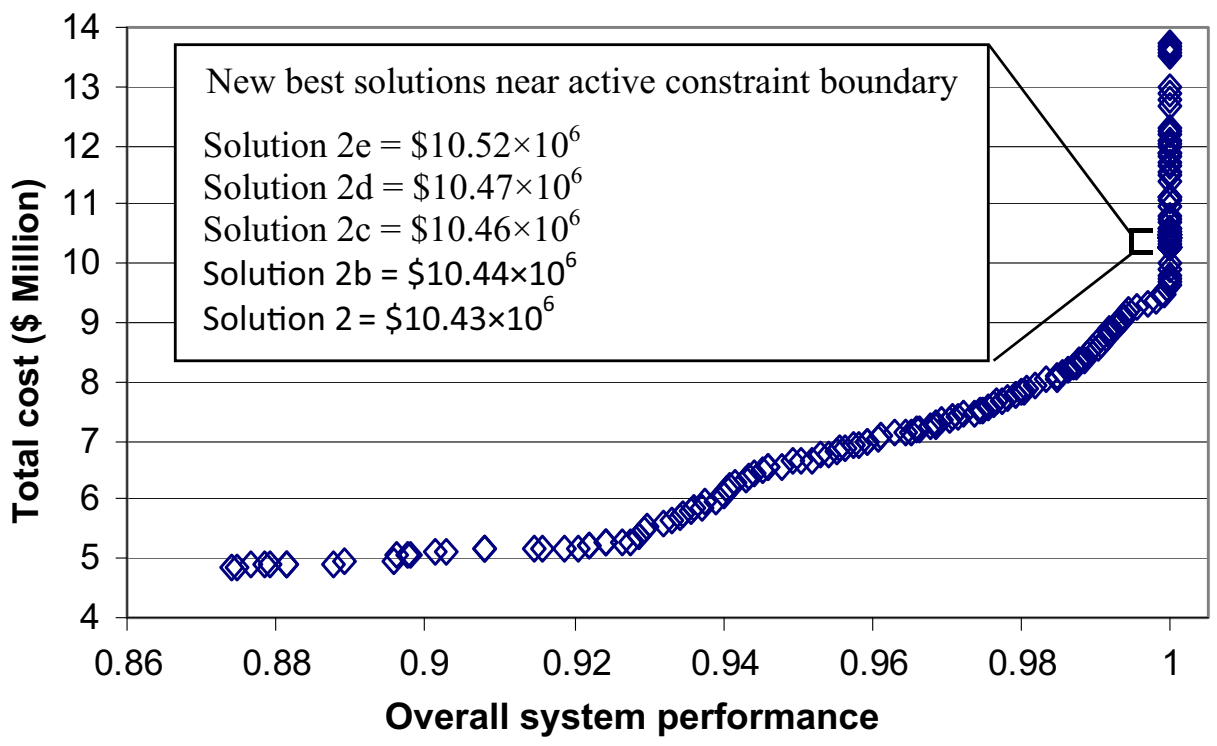

(b) Sample Pareto-optimal front achieved by the proposed method

Fig. 1 The Anytown water distribution network. Solutions with system performance values less than unity are infeasible. Tanks 41 and 42 are existing tanks

Tanyimboh 2010a). This approach avoids the problems of tank flow imbalances (e.g. Murphy et al. 1994; Walters et al. 1999; Kurek and Ostfeld 2013). 
Moreover, the philosophy here is different (Siew and Tanyimboh 2010b). For example, constraints to balance the respective initial and final water levels in the tanks and are not required. Similarly, a constraint to balance the total inflow and outflow volumes of the tanks for the network as a whole is not required. In addition to pressure-driven extended-period simulation, we have incorporated criteria that promote tank depletion and replenishment in the objective function (Section 4). Accordingly, solutions having tanks with excessive cost, insufficient or excessive elevation, insufficient or excessive capacity, partial depletion or partial replenishment are optimized out seamlessly through natural selection. If a candidate solution has a new tank, the solution's chromosome specifies the site and other relevant parameters. The pressure-driven hydraulic simulator together with penalty-free Pareto dominance permits any solution (feasible or infeasible) to be rated realistically and without bias.

It may be recalled that in extended-period simulation, a snapshot analysis is executed the beginning of a hydraulic time step and the system is checked for any status changes during the hydraulic time step. If, for example, the water level in a new tank reaches the minimum level before the end of the time step, the tank's riser is temporarily closed and an additional snapshot analysis is performed due to the changed system state. This sequence is carried out in each hydraulic time step in the extended-period simulation. This is the standard procedure for extended-period simulation in EPANET-PDX (a pressure-driven hydraulic simulation model developed in the present research) (Siew and Tanyimboh 2010a, 2012b). Conceptually the extended period simulation procedure is the same as in EPANET 2. Tank designs achieved at the end of the optimization are final and no further tank adjustments (as in e.g. VamvakeridouLyroudia et al. 2005) are required.

New tanks were assumed to be cylindrical. Four design variables for the new tanks were used as follows (Vamvakeridou-Lyroudia et al. 2005; Prasad 2010).

(a) Total volume $(V)$;

(b) Ratio of diameter to height $(D / H)$;

(c) Ratio of emergency volume to total volume $(v / V)$; and

(d) Level of the bottom of the tank (i.e. the tank's elevation).

Upper and lower bounds on the shape parameter $D / H$ and emergency storage fraction $v / V$ were employed to avoid solutions that may be undesirable in practice (Prasad 2010). All nodes except those already connected directly to an existing tank were considered as possible locations for new tanks. Table 1 summarizes the decision variables of the optimization problem. The range of tank volumes and their associated costs was taken from Walski (1987). Intermediate tank sizes were considered here and corresponding costs were interpolated linearly. The tank-sizing decision variables were discretized to provide eight options per decision variable (Table 2).

\section{Formulation of the Optimization Model}

The objective is to upgrade the system to meet future demands and pressure in the most economical way, considering both capital expenditure and operational costs. The procedure developed is based on two primary objectives. The first objective minimises the total cost. The second objective aims to improve the system's performance. The formulation of the second objective function involves normalising the operational constraints and combining the normalised operational constraints with a measure of hydraulic performance i.e. the demand satisfaction ratio. The demand satisfaction ratio, derived by pressure-driven analysis (see e.g. 
Table 1 Overview of the decision variables

\begin{tabular}{ll}
\hline Variables & Explanations \\
\hline Existing pipes & 35 pipes to be considered for paralleling or cleaning and relining \\
New pipes & 6 pipes to be sized \\
Existing tanks & Operation of 2 tanks to be optimized \\
New tanks & Up to 2 tanks to be sized and located, and their operation optimized \\
New tank risers & Tank risers to be sized for the new tanks \\
Tank sizing parameters & $V, D / H, v / V$ and elevation \\
Existing pumps & Operation of 3 pumps to be optimized \\
New pumps & Up to 2 pumps to be added to the station and their operation optimized \\
Pump status & 8 ON-OFF control variables per pump \\
\hline
\end{tabular}

Gupta and Bhave 1996; Giustolisi et al. 2008; Gorev and Kodzhespirova 2013; Kovalenko et al. 2014; Ciaponi et al. 2015), is the ratio of the flow delivered to the flow required (Ackley et al. 2001; Tanyimboh et al. 2003; Kalungi and Tanyimboh 2003; Tanyimboh and Templeman 2010). The demand satisfaction ratio is also known as the available demand fraction (see e.g. Abdy Sayyed et al. 2015; Gupta 2015).

The first objective function $f_{1}$ represents the total cost while the second objective function $f_{2}$ represents the system's performance; $f_{1}$ is minimized and $f_{2}$ is maximized.

$$
\begin{aligned}
& f_{1}=\chi^{2} \\
& f_{2}=\pi^{4}
\end{aligned}
$$

where $\chi$ and $\pi$ are the normalised total cost and system performance functions, respectively. The exponents 2 and 4, in Eqs. 1 and 2 respectively, are default empirically derived values in Siew and Tanyimboh (2012a). For solution $i$,

$$
\chi_{i}=\frac{C_{i}}{C_{\max }} ; \quad i=1, \ldots, N I
$$

where $N I$ is the number solutions, $C_{i}$ is the total cost for solution $i$ and $\chi_{i}$ is the normalised total cost. This includes all the costs incurred (i.e. pipes, pumps, tanks, energy, etc.). The present

Table 2 Tank costs and associated discrete decision variable options

\begin{tabular}{lllll}
\hline Total volume options $\left(\mathrm{m}^{3}\right)$ & Costs $\left(\$ \times 10^{3}\right)$ & Elevation options $(\mathrm{m})$ & $D / H$ options & $v / V$ options \\
\hline 227.28 & 115.0 & 54.864 & 0.75 & 0.25 \\
454.56 & 145.0 & 57.912 & 0.85 & 0.30 \\
909.12 & 265.0 & 60.960 & 0.95 & 0.35 \\
$1,136.40$ & 325.0 & 64.008 & 1.05 & 0.40 \\
$1,590.95$ & 365.0 & 67.056 & 1.25 & 0.45 \\
$2,272.79$ & 425.0 & 70.104 & 1.35 & 0.50 \\
$3,409.19$ & 512.5 & 73.152 & 1.40 & 0.55 \\
$4,545.58$ & 600.0 & 76.200 & 1.50 & 0.60 \\
\hline
\end{tabular}

Conversion factors: $1 \mathrm{gal}=0.004546 \mathrm{~m}^{3}$ and $1 \mathrm{ft}=0.3048 \mathrm{~m}$ (Walski 1987) 
worth of energy costs is based on an interest rate of $12 \%$ and an amortisation period of 20 years. Details of the costs of pipe paralleling, cleaning and lining, pump operation and tanks are available in Walski (1987). $C_{\max }$ is the cost of the most expensive of solutions in the population.

We investigated two alternative definitions of the system performance function $\pi$ in Eq. 2 . For solution $i$, where $N I$ is the number solutions,

$$
\pi_{i}=\frac{1}{2}\left(\frac{1}{N L} \sum_{l=1}^{N L} \mu_{l}+\frac{1}{N R} \sum_{r=1}^{N R} \rho_{r}\right) ; \quad i=1, \ldots, N I
$$

where $N L$ is the number of loading conditions (e.g. average day, peak flow, etc.), $N R$ is the number of service reservoirs or tanks. For service reservoir $r, \rho_{r}$ is the replenishment ratio; i.e. the ratio of the volume of water at the end of the last hour of the extended-period simulation to the total operational water volume. This criterion aims to refill each reservoir at the end of the operational cycle (typically 24 hours). For loading condition $l, \mu_{l}$ is the average network demand satisfaction ratio; i.e. the ratio of the available flow to the demand and is derived from the pressure-driven simulation model. Maximizing this criterion aims to satisfy all the nodal demands (Ackley et al. 2001). In this way, the minimum node pressure constraints are addressed seamlessly (Siew and Tanyimboh 2012a; Siew et al. 2014).

The average network demand satisfaction ratio $\mu_{l}$ for loading condition $l$ is

$$
\mu_{l}=\frac{1}{N T_{l}} \sum_{t=1}^{N T_{l}} \sigma_{t} ; l=1, \ldots, N L
$$

For hydraulic time step $t, \sigma_{t}$ is the network demand satisfaction ratio; and $N T_{l}$ is the number of hydraulic time steps for loading condition $l$. The parameters $\mu_{l}, \rho_{r}$ and $\sigma_{t}$ all have values between 0 and 1. Hence, the system performance function $\pi_{i}$ (Eq. 4 ) reaches a maximum value of 1 when all the criteria defined are met. As $\pi_{i}$ comprises normalised necessary conditions, additional weights or coefficients are not required.

The system performance function $\pi_{i}$ may achieve fully feasible solutions. However, the solutions so obtained need not make full use of the variable storage of the service reservoirs during the average day. Therefore, to improve the formulation further, an additional criterion was introduced in Eq. 6 to promote service reservoir depletion.

$$
\pi_{i}=\frac{1}{3}\left(\frac{1}{N L} \sum_{l=1}^{N L} \mu_{l}+\frac{1}{N R} \sum_{r=1}^{N R}\left(\rho_{r}+\delta_{r}\right)\right) ; i=1, \ldots, N I
$$

For service reservoir $r, \delta_{r}$ is the depletion ratio i.e. the ratio of the maximum cumulative depletion achieved for the average-day flow to the total operational volume. This criterion promotes cost effectiveness and improves water quality through full depletion of the service reservoirs in each cycle (see e.g. Edwards and Maher 2008).

\section{Computational Solution of the Optimization Problem}

We used a genetic algorithm PF-MOEA (penalty-free multi-objective evolutionary algorithm) developed in this research (Siew and Tanyimboh 2012a; Siew et al. 2014) to solve the 
optimization problem. PF-MOEA is based on NSGA II (non-dominated sorting genetic algorithm) (Deb et al. 2002). PF-MOEA rates all solutions according to the performance function $\pi_{i}$ (Eq. 4 or 6) followed by Pareto dominance based purely on the performance and cost functions $\pi_{i}$ and $\chi_{i}$.

The pressure-driven hydraulic simulator EPANET-PDX (Siew and Tanyimboh 2012b; Seyoum and Tanyimboh 2014) is embedded in PF-MOEA. The pressure-driven hydraulic simulator provides a realistic assessment of the hydraulic properties of the solutions with insufficient flow and pressure as it takes account of the relationship between the pressure at a demand node and the flow that is available (see e.g. Elhay et al. 2016). Unlike NSGA II (Deb et al. 2002), PF-MOEA rates both feasible and infeasible solutions strictly according to their cost effectiveness. Accordingly, in PF-MOEA all feasible and infeasible non-dominated solutions are considered superior to all feasible and infeasible dominated solutions. In other words, non-dominated infeasible solutions are considered superior to dominated feasible solutions. Additional details on the methodology and its effectiveness are available in Siew and Tanyimboh (2012a) and Siew et al. (2014). Also, demonstrations of the effectiveness of an alternative penalty-free formulation that uses the EPANET 2 hydraulic simulator are available in Saleh and Tanyimboh $(2013,2014,2016)$. The hydraulic modelling approach in EPANET 2 assumes that the flow that is available at a demand node is the same as the demand and is thus characterised as demand-driven analysis (see e.g. Spiliotis and Tsakiris 2011).

We wrote the program for the genetic algorithm in C++ (Siew and Tanyimboh 2012a). We used binary coding and the operators were single-bit mutation, single-point crossover and binary tournament selection for crossover. The population size was 200; crossover probability was 1 ; and mutation rate was $0.005 ; 15$ optimization runs with different initial populations were conducted for each formulation (Eqs. 4 and 6) of the performance function $\pi_{i}$. The members of the initial populations were selected randomly except for the minimum and maximum solution vectors that are always included by default. Each decision variable in the minimum solution vector has the smallest permissible value within the solution space. Similarly each decision variable in the maximum solution vector has the largest permissible value within the solution space.

Each optimization run lasted 5,000 generations i.e. one million function evaluations. We carried out extended-period simulation with a hydraulic time step of one hour for the 24-hour average-day flow. Previous studies used hydraulic time steps of three hours (VamvakeridouLyroudia et al. 2005; Prasad 2010) and six hours (Walters et al. 1999). Also, we used a hydraulic time step of 30 minutes for the fire flows. A personal computer (Intel Core 2 Duo, CPU 2.66 GHz, RAM 3.23 GB) was used for this study. A typical optimization run required on average 22.7 hours; i.e. 16.36 seconds per generation or 0.08 seconds per function evaluation.

\section{Results and Discussion}

The solutions achieved were assessed further by investigating the spatial and temporal variations of the water age, chlorine residual and disinfection by-products for the averageday flow in the hydraulic simulator EPANET 2 (Rossman 2002). Complete mixing was assumed for all tanks. All water quality simulations were run for 72 hours to enable the results to stabilize. Results for the last 24 hours are presented here. For the water quality simulations, both the hydraulic and water quality time steps were one minute. Bulk and wall reaction rate 
constants of 0.5/day and $0.1 \mathrm{~m} /$ day, respectively, were assumed (Carrico and Singer 2009). To ensure the chlorine residual at all demand nodes and tanks remained just above $0.2 \mathrm{mg} / \mathrm{L}$ (WHO 2011) the chlorine concentration at the treatment plant was kept constant at $0.6 \mathrm{mg} / \mathrm{L}$. A maximum total THM (trihalomethane) concentration of $100 \mu \mathrm{g} / \mathrm{L}$ (European 1998) was adopted. For water age and THM, initial values of zero were assumed for all nodes and tanks. The 72-hour extended-period simulation in EPANET 2 required 1.6 seconds for water age, 1.3 seconds for chlorine and 2 seconds for THM, on an Intel Xeon workstation (with two processors of CPU $2.4 \mathrm{GHz}$ and RAM of $16 \mathrm{~GB}$ ). To avoid misunderstanding, this workstation was used for the water quality modelling only. The other aspects i.e. optimization and results verification were performed on the $P C$ (personal computer) mentioned previously in Section 5 .

Two of the best solutions achieved i.e. Solutions 1 and 2, are presented and discussed in detail. These solutions are fully feasible as they do not violate any node pressure constraints while operating under all five loading conditions and all tanks fully refill for the average-day 24-hour cycle. Both solutions have been simulated with a hydraulic time step of one minute to confirm their feasibility. Figure $1 \mathrm{~b}$ shows the Pareto-optimal front from which Solution 2 was obtained. The optimization algorithm consistently found many feasible designs as in Fig. 1b. Therefore, post-optimization, artificially stringent criteria were adopted for the hydraulic simulations of the solutions achieved. Aside from Solution 2, there are many fully feasible designs in the same optimization run that are cheaper than the previous best solution in the literature. Table 3 provides a cost comparison with the previous best solutions.

The algorithm also achieved consistently many competitive solutions that are feasible based on larger hydraulic simulation time steps of 30 or 60 minutes. Two such solutions, i.e. Solutions 3 and 4, from different optimization runs, are included for completeness but not discussed in detail. All solutions presented are cheaper than the cheapest feasible solution reported in the literature to date with a total cost of $\$ 10.59$ million (Prasad 2010). Solutions 1, 2 and 4 achieved the lowest tank costs compared to previous published solutions. The least cost solution achieved (Solution 1) has a total cost of $\$ 10.31$ million. New pumps were not required and a single new tank was added.

Table 3 Cost comparison with previous best solutions

\begin{tabular}{|c|c|c|c|c|}
\hline \multirow[t]{2}{*}{ Solutions } & \multicolumn{4}{|c|}{ Costs (\$ Millions) } \\
\hline & Pipes & Energy & Tanks & Total \\
\hline Murphy et al. (1994) & 4.51 & 5.97 & 0.86 & 11.34 \\
\hline Walters et al. (1999) & 4.10 & 5.90 & 0.90 & 10.90 \\
\hline Prasad (2010) & 3.58 & 6.24 & 0.78 & 10.59 \\
\hline Vamvakeridou-Lyroudia et al. (2005) ${ }^{\mathrm{a}}$ & 3.78 & 6.15 & 0.61 & 10.54 \\
\hline Solution 1 & 3.68 & 6.12 & 0.51 & 10.31 \\
\hline Solution $2^{\mathrm{b}}$ & 3.68 & 6.22 & 0.51 & 10.41 \\
\hline Solution 3 & 3.58 & 6.22 & 0.54 & 10.34 \\
\hline Solution $4^{\mathrm{b}}$ & 3.66 & 6.23 & 0.51 & 10.40 \\
\hline
\end{tabular}

\footnotetext{
a Solution with "small" pressure deficiencies at two nodes-deemed infeasible
}

${ }^{\mathrm{b}}$ Solutions with tank depletion criterion 
Table 4 Pipe upgrading and rehabilitation results

\begin{tabular}{|c|c|c|c|c|c|c|}
\hline & \multicolumn{3}{|c|}{ Solution 1} & \multicolumn{3}{|c|}{ Solution 2} \\
\hline & Pipe ID & Length (m) & Diameter (m) & Pipe ID & Length (m) & Diameter $(\mathrm{m})$ \\
\hline \multirow[t]{5}{*}{ PP } & 1 & 3657.42 & 0.3556 & 2 & 3657.42 & 0.6096 \\
\hline & 2 & 3657.42 & 0.6096 & 4 & 30.48 & 0.2032 \\
\hline & 20 & 1828.71 & 0.4064 & 17 & 3657.42 & 0.2032 \\
\hline & 23 & 1828.71 & 0.3556 & 20 & 1828.71 & 0.6096 \\
\hline & 26 & 1828.71 & 0.6096 & 26 & 1828.71 & 0.6096 \\
\hline $\mathrm{CL}$ & 40 & 30.48 & 0.3048 & 3 & 3657.42 & 0.4064 \\
\hline \multirow[t]{7}{*}{$\mathrm{NP}$} & 10 & 1828.71 & 0.3556 & 10 & 1828.71 & 0.1524 \\
\hline & 13 & 1828.71 & 0.1524 & 13 & 1828.71 & 0.254 \\
\hline & 14 & 1828.71 & 0.1524 & 14 & 1828.71 & 0.2032 \\
\hline & 15 & 1828.71 & 0.254 & 15 & 1828.71 & 0.4572 \\
\hline & 16 & 1828.71 & 0.3556 & 16 & 1828.71 & 0.2032 \\
\hline & 25 & 2743.07 & 0.1524 & 25 & 2743.07 & 0.2032 \\
\hline & ${ }^{\mathrm{a}}$ Riser 7 & 30.78 & 0.4064 & ${ }^{\mathrm{a}}$ Riser 6 & 30.78 & 0.3048 \\
\hline
\end{tabular}

1 in $=0.0254 \mathrm{~m}$

$\mathrm{PP}=$ Pipe paralleling

$\mathrm{CL}=$ Pipe cleaning and lining

$\mathrm{NP}=$ New pipes

${ }^{\text {a }}$ Risers 6 and 7 are risers for new tanks located at nodes 6 and 7 respectively

Maximum velocity constraints were not considered herein as they are not in the original problem specification (Walski 1987). However, all solutions presented have average day flows with velocities less than $2 \mathrm{~m} / \mathrm{s}$ (Prasad 2010). Take Solution 2 for instance whose maximum flow velocity is $1.51 \mathrm{~m} / \mathrm{s}$ in pipe 4 at the 10th hour when the demand factor of 1.3 is the highest. Pipe 4 connects node 1 to the pumping station.

Pipe upgrading and rehabilitation details for the best two solutions are summarized in Table 4. The values of the pipe diameters in Table 4 have been converted from inches to metres; the pipe sizes are in fact discrete. The results generally appear to suggest that pipe paralleling (PP) is preferred to cleaning and lining (CL). In each of Solutions 1 and 2, only one pipe was selected for cleaning and lining (Table 4).

Table 5 Properties of the new tanks

\begin{tabular}{llc}
\hline Properties & Solution 1 & Solution 2 \\
\hline Maximum operating water level (m) & 72.98 & 72.98 \\
Minimum operating water level (m) & 67.18 & 66.56 \\
Top level (m) & 74.31 & 74.31 \\
Bottom level (m) & 60.96 & 60.96 \\
Diameter (m) & 18.67 & 18.67 \\
Tank location & Node 7 & Node 6 \\
\hline
\end{tabular}

$1 \mathrm{ft}=0.3048 \mathrm{~m}$ 


\section{Solution 1}
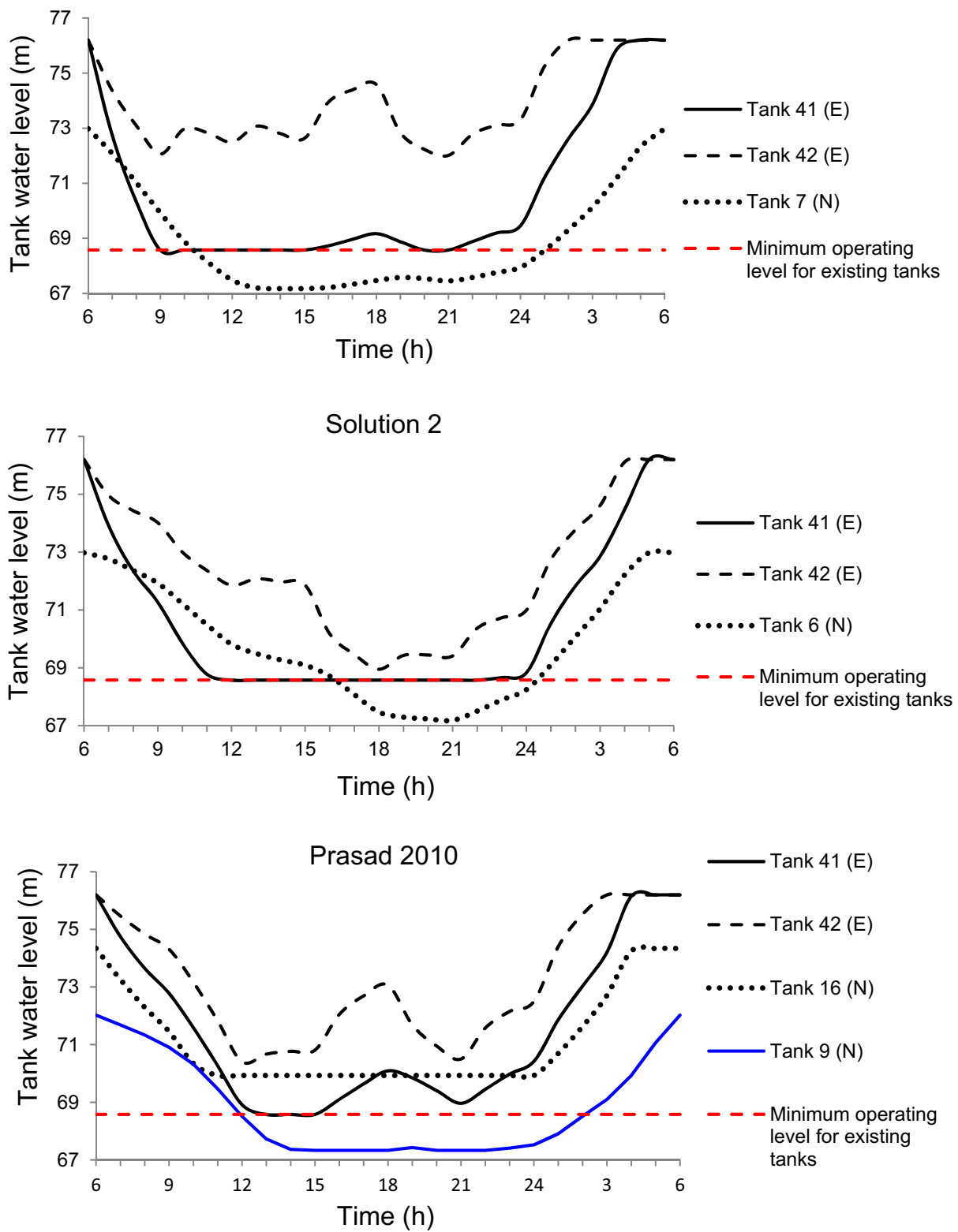

Fig. 2 Water levels in the tanks for the average day flow. (E) and (N) refer to existing and new tanks respectively

Solution 1 is the cheapest solution achieved at a total cost of $\$ 10.31$ million. Unlike most previous solutions in the literature with two tanks (e.g. Prasad 2010), a single new tank was added at node 7 (Tank $7(\mathrm{~N})$ hereafter). No new pumps were added to the pumping station. One of the three existing pumps operates when demands are high from 9 a.m. to 6 p.m. i.e. nine hours and the remaining two 
Table 6 Optimized pumping schedules

\begin{tabular}{llllll}
\hline Solutions & \multicolumn{2}{l}{ Number of pumps operating } & & Energy consumption (kWh/day) \\
\cline { 2 - 5 } & $6-9 \mathrm{~h}$ & $9-15 \mathrm{~h}$ & $15-18 \mathrm{~h}$ & $18-6 \mathrm{~h}$ & \\
\hline 1 & 2 & 3 & 3 & 2 & $18,733.50$ \\
$2^{\mathrm{a}}$ & 3 & 3 & 2 & 2 & $19,017.92$ \\
\hline
\end{tabular}

${ }^{\text {a }}$ Solution with tank depletion criterion

operate for the entire 24 hours. The pumps collectively use $18,733.5 \mathrm{kWh}$ of energy per day (Table 5).

The pump operation strategy achieved is somewhat different from other solutions published in the literature (e.g. Walters et al. 1999) where the third pump is usually switched on during the low demand period to re-fill the tanks. Herein, for Solution 1, additional flow during the peak demand hours is supplied by both the new tank and the third pump. Probably this could be the reason why the algorithm only allocated one new

Table 7 Minimum pressures for the various loading conditions

\begin{tabular}{|c|c|c|c|c|c|}
\hline \multirow[t]{2}{*}{ Solutions } & \multicolumn{5}{|c|}{ Residual heads at the critical nodes (m) } \\
\hline & $\begin{array}{l}\text { Average day flow } \\
\text { ( } 24 \text { hour EPS) }\end{array}$ & $\begin{array}{l}\text { Instantaneous peak } \\
\text { flow (SSS) }\end{array}$ & $\begin{array}{l}\text { Fire flow } 1 \\
\text { ( } 2 \text { hour EPS) }\end{array}$ & $\begin{array}{l}\text { Fire flow } 2 \\
\text { ( } 2 \text { hour EPS) }\end{array}$ & $\begin{array}{l}\text { Fire flow } 3 \\
\text { ( } 2 \text { hour EPS) }\end{array}$ \\
\hline $\begin{array}{l}\text { Solution } \\
\quad 1\end{array}$ & $28.96(16)$ & $28.19(9)$ & $15.16(16)$ & $16.70(16)$ & $22.50(11)$ \\
\hline $\begin{array}{l}\text { Solution } \\
2\end{array}$ & $28.29(16)$ & $29.91(9)$ & $17.10(16)$ & $16.61(7)$ & $21.66(9)$ \\
\hline $\begin{array}{l}\text { Solution } \\
2 \mathrm{~b}\end{array}$ & $28.27(16)$ & $30.89(11)$ & $16.73(16)$ & $15.78(7)$ & $18.30(11)$ \\
\hline $\begin{array}{l}\text { Solution } \\
2 \mathrm{c}\end{array}$ & $28.27(16)$ & $30.82(11)$ & $16.70(16)$ & $18.53(5)$ & $18.29(11)$ \\
\hline $\begin{array}{l}\text { Solution } \\
2 \mathrm{~d}\end{array}$ & $28.27(16)$ & $30.85(11)$ & $16.69(16)$ & $18.53(5)$ & $18.28(11)$ \\
\hline $\begin{array}{l}\text { Solution } \\
2 \mathrm{e}^{*}\end{array}$ & $28.31(16)$ & $31.12(11)$ & $17.43(16)$ & $16.89(7)$ & $19.34(11)$ \\
\hline $\begin{array}{l}\text { Solution } \\
3^{*}\end{array}$ & $29.59(16)$ & $32.48(16)$ & $17.15(16)$ & $20.15(16)$ & $20.54(9)$ \\
\hline $\begin{array}{l}\text { Solution } \\
4^{*}\end{array}$ & $28.99(16)$ & $31.44(16)$ & $15.37(16)$ & $16.92(16)$ & $20.75(11)$ \\
\hline
\end{tabular}

$1 \mathrm{psi}=0.703 \mathrm{~m}$

The figures in parentheses represent the critical nodes i.e. the nodes with the smallest pressures

The required pressure is $28.12 \mathrm{~m} \mathrm{(40} \mathrm{psi)} \mathrm{for} \mathrm{average} \mathrm{day} \mathrm{and} \mathrm{instantaneous} \mathrm{peak} \mathrm{flows;} \mathrm{and} 14.06 \mathrm{~m}$ (20 psi) for all fire flows

EPS - extended period simulation

SSS - single snapshot simulation

* Solutions simulated using 1 hour hydraulic time step

Solutions 2, 2b-e were achieved together in one optimization run 

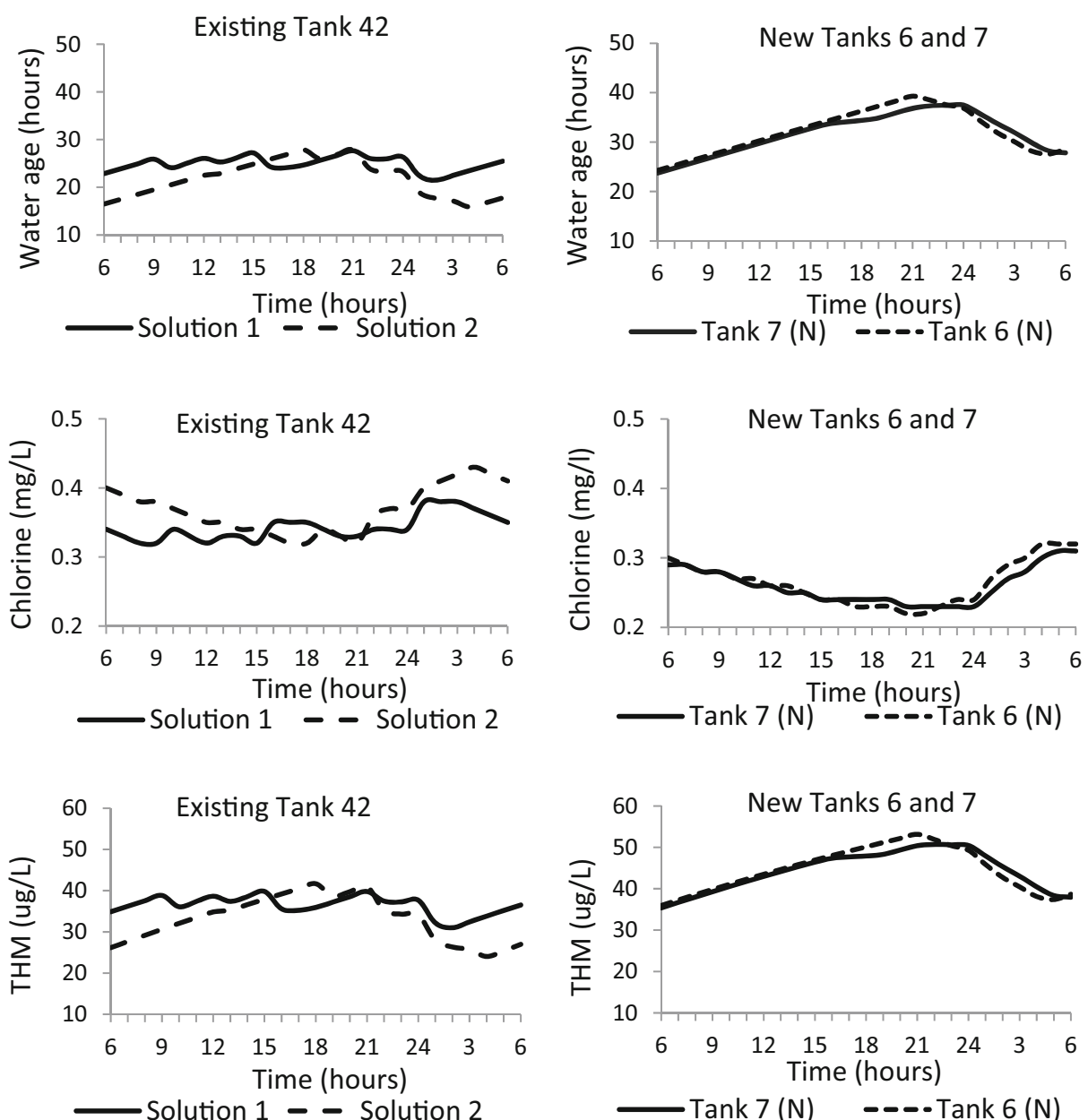

Fig. 3 Water quality variations in the tanks

tank instead of two as in some of the previous solutions (Prasad 2010; VamvakeridouLyroudia et al. 2005; Murphy et al. 1994).

Table 5 provides details of the new tank. Figure 2a shows the tank operating levels over a cycle of 24 hours for the average day flow. All tanks refill fully by the end of the day. The new Tank 7(N) and existing Tank 41 (Tank 41(E) hereafter) drain rapidly (approximately 6 and 3 hours respectively). The water level in existing Tank 42 (Tank 42(E) hereafter) fluctuates and only approximately $40 \%$ of the total operational volume is utilised. For comparison purposes, the tank operations from Prasad (2010) are presented also in Fig. 2c. It is evident that the capacity of Tank 42(E) is not fully utilised. Similarly, the best solution in Vamvakeridou-Lyroudia et al. (2005) has this weakness for the average day and two fire flows. The above-mentioned solutions including Solution 1 are thus undesirable from the standpoint of tank operation and water quality. 


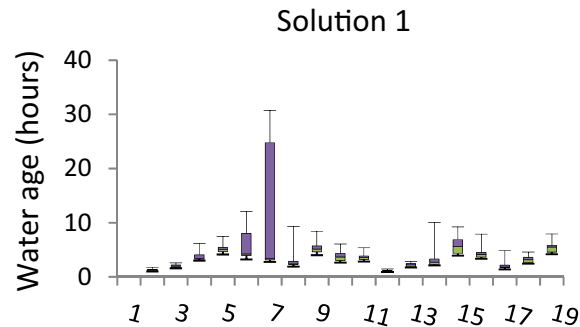

Demand nodes

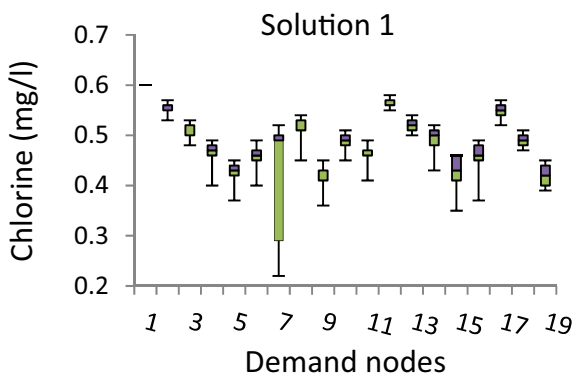

Solution 1

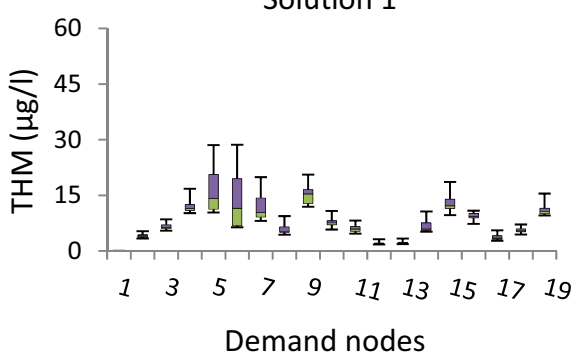

Solution 2

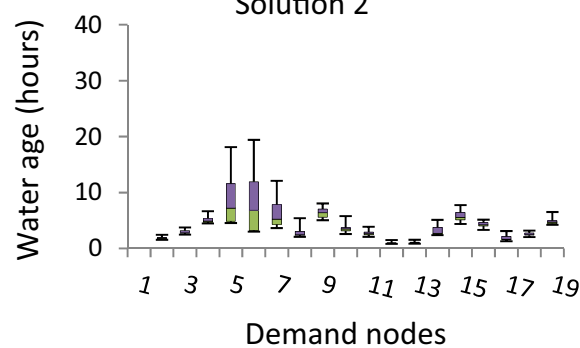

Solution 2

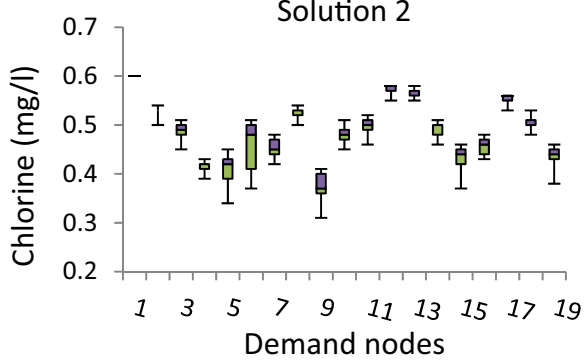

Solution 2

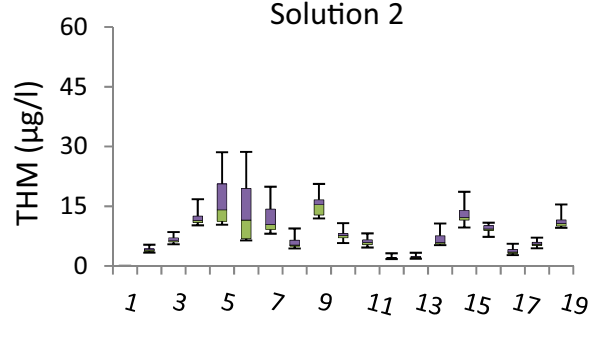

Demand nodes

Fig. 4 Water quality variations at the demand nodes over 24 hours

Solution 2 costing $\$ 10.41$ million was the cheapest feasible solution achieved with the enhanced performance function in Eq. 6. One new tank was added at node 6, i.e. Tank $6(\mathrm{~N})$. No new pumps were added; the pumping cost is slightly higher than Solution 1. All three pumps operate from 6 a.m. to 3 p.m. i.e. nine hours when the demands are high. Only two pumps are required for the rest of the day (Table 6). Costs for the new tank and pipe rehabilitation are similar to Solution 1.

Figure $2 \mathrm{~b}$ shows the operation cycles of the tanks for the average-day flow for Solution 2. The available operational volumes for all three tanks are utilised effectively. Indeed the water level in existing Tank 42(E) reaches a minimum level of $0.21 \mathrm{~m}$ above the minimum operating level. This shows that the proposed new formulation in Eq. 6 with the tank depletion criterion is advantageous. The Appendix shows the tank operations for the three fire flows. The total emergency storage provided by the tanks satisfies the fire flows. Existing Tanks 41(E) and 42(E) drain fully in each case. The new Tank 6(N) reaches a maximum depletion of approximately $90 \%$ at the end of Fire-flow 2 . 
Table 7 provides the values of the pressures at the most critical nodes for the various loading conditions and shows that all the solutions satisfy the pressure requirements in full. Results presented herein are based on steady state and extended period simulations (with a hydraulic time step of one minute unless otherwise stated) performed with EPANET-PDX. Also, the solutions were re-checked in EPANET 2 that gave the same results. For the results verification, a 24 hour extended-period simulation with a hydraulic time step of one minute took 0.843 seconds in EPANET-PDX on the PC.

Over the 24 hour cycle (with hydraulic time step of one minute) the pumps of Solution 1 operate consistently near their best efficiency point of $65 \%$ and do not drop below $60.5 \%$. For Solution 2, the efficiency of the three pumps varies between 60 and $65 \%$ throughout the 24 hour operating cycle. Aside from the ON-OFF status variables for pump scheduling in Table 1, no extraneous operational constraints were applied to the pumps. For example, Prasad (2010) and Vamvakeridou-Lyroudia et al. (2005) used a constraint on the pump operational capacity to meet daily demand variation.

Finally, in terms of water quality, Fig. 3 shows the two new tanks 6(N) and 7(N) are generally comparable. On the other hand water quality is better in the existing Tank 42(E) in Solution 2 due to the criterion that promotes tank depletion. Also Fig. 4 suggests that in Solution 1 the water quality at node 7 would have the largest deviation from the average among all the demand nodes in both Solutions 1 and 2. These results seem to suggest that overall, considering both the tanks and demand nodes, Solution 2 is better. However, without additional investigations it is difficult to say whether the improved formulation of the performance function $\pi_{i}$ in Eq. 6 is the most dominant factor. Figure 5 shows the depletion of the emergency storage for Solution 2, for the three fire-fighting flow scenarios.

\section{Conclusions}

This article concerns the development and application of a new multi-objective evolutionary optimization approach for the design and upgrading of water distribution systems with multiple pumps and service reservoirs. The tank siting and design methodology was based on pressuredriven extended-period simulation and was shown to be highly effective and the performance of the pumps was consistently efficient. Explicit criteria for the depletion and replenishment of the service reservoirs were included in the optimization model. The optimization procedure developed achieved many optimal and near optimal solutions consistently when applied to the benchmark Anytown water distribution network. The new best solutions found for the Anytown network were competitive and fully feasible. The advantages of the proposed new approach are that it is practical and generic.

Acknowledgments The authors are grateful to the UK Engineering and Physical Sciences Research Council (EPSRC Grant Number EP/G055564/1), the British Government (Universities UK, Overseas Research Students' Award Scheme) and the University of Strathclyde Glasgow for funding this research. This research was carried out in collaboration with Veolia (now Affinity) Water.

All relevant data are included in this paper.

\section{Compliance with Ethical Standards}

Conflict of Interest There is no conflict of interest. 


\section{Appendix: Emergency Storage Depletion During Fire Flows}

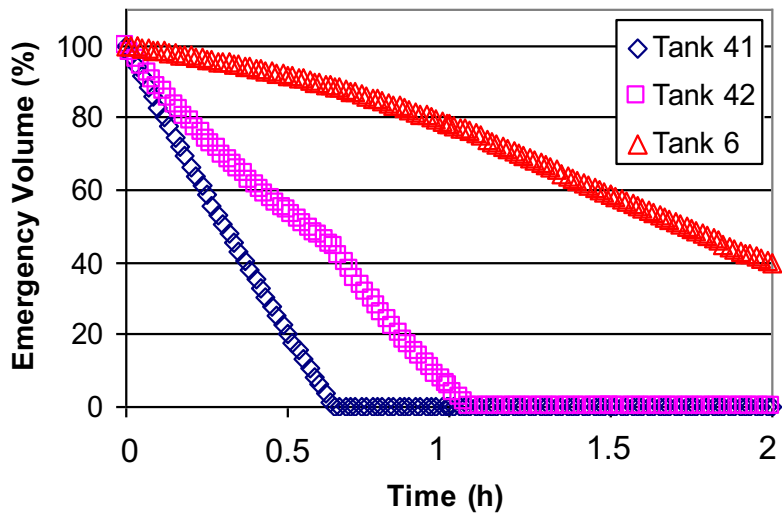

(a) Fire Flow 1

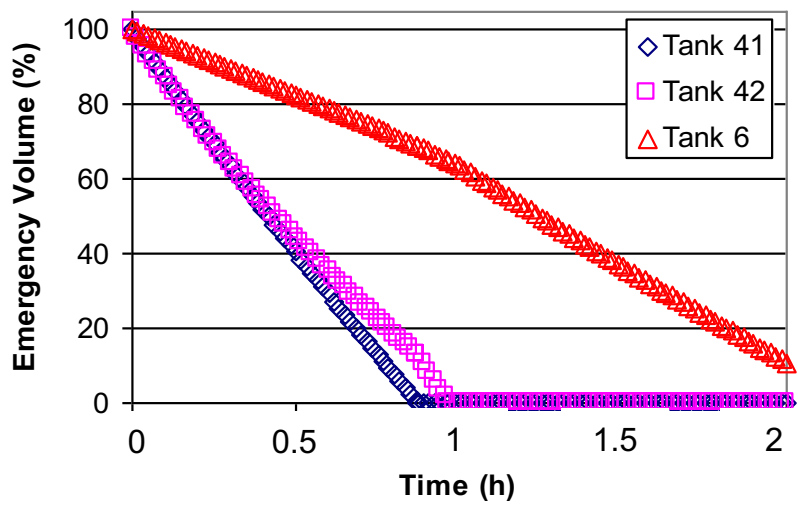

(b) Fire Flow 2

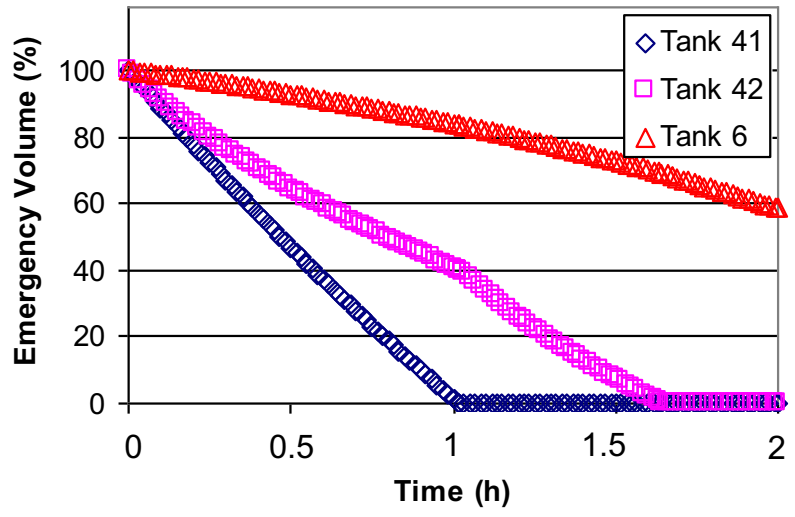

(c) Fire Flow 3

Fig. 5 Emergency storage depletion in Solution 2 during the fire flows. Tanks 41 and 42 are existing tanks; Tank 6 is new 
Open Access This article is distributed under the terms of the Creative Commons Attribution 4.0 International License (http://creativecommons.org/licenses/by/4.0/), which permits unrestricted use, distribution, and reproduction in any medium, provided you give appropriate credit to the original author(s) and the source, provide a link to the Creative Commons license, and indicate if changes were made.

\section{References}

Abdy Sayyed MA, Gupta R, Tanyimboh TT (2015) Noniterative application of EPANET for pressure dependent modelling of water distribution systems. Water Resour Manag 29(9):3227-3242. doi:10.1007/s11269-015-0992-0

Ackley JRL, Tanyimboh TT, Tahar B, Templeman AB (2001) Head-driven analysis of water distribution systems. Water Softw. Sys.: Theory and Applications, Vol. 1, Ulanicki, B., Coulbeck, B., and Rance, J. (eds.), Research Studies Press Ltd, England, ISBN 0863802745, Chapter 3:183-192

Atkinson S, Farmani R, Memon FA, Butler D (2014) Reliability indicators for water distribution system design: comparison. J Water Resour Plan Manag 140(2):160-168

Carrico B, Singer PC (2009) Impact of booster chlorination on chlorine decay and THM production: simulated analysis. J Environ Eng 135(10):928-935

Ciaponi C, Franchioli L, Murari E, Papiri S (2015) Procedure for defining a pressure-outflow relationship regarding indoor demands in pressure-driven analysis of water distribution networks. Water Resour Manag 29:817-832. doi:10.1007/s11269-014-0845-2

Deb K, Pratap A, Agarwal S, Meyarivan T (2002) A fast and elitist multiobjective genetic algorithm: NSGA-II. Evol Comp, IEEE Trans 6(2):182-197

Dridi L, Parizeau M, Maihot A, Villeneuve J-P (2008) Using evolutionary optimization techniques for scheduling water pipe renewal considering a short planning horizon. Comput-Aided Civ Infrastruct Eng 23(8):625-663

Edwards J, Maher J (2008) Water quality considerations for distribution system storage facilities. Am Water Works Assoc J 100(7):60

Elhay S, Piller O, Deuerlein J, Simpson A (2016) A robust, rapidly convergent method that solves the water distribution equations for pressure-dependent models. J. Water Resour Plan Manag 142(2). doi: 10.1061/ (ASCE)WR.1943-5452.0000578

European Community (1998) Council Directive 98/83/EC on the quality of water intended for human consumption. Official Journal of the European Communities L330

Farmani R, Walters GA, Savic DA (2005) Trade-off between total cost and reliability for Anytown water distribution network. J Water Resour Plann Manag 131(3):161-171

Farmani R, Walters GA, Savic DA (2006) Evolutionary multi-objective optimization of the design and operation of water distribution network: total cost vs. reliability vs. water quality. J Hydroinform 8:165-179

Giustolisi O, Savic DA, Kapelan Z (2008) Pressure-driven demand and leakage simulation for water distribution networks. J Hydraul Eng 134(5):626-635

Gorev NB, Kodzhespirova IF (2013) Noniterative implementation of pressure-dependent demands using the hydraulic analysis engine of EPANET 2. Water Resour Manag 27(10):3623-3630

Gupta R (2015) History of pressure-dependent analysis of water distribution networks and its applications. World Environ Water Resour Congress 2015:755-765. doi:10.1061/9780784479162.070

Gupta R, Bhave PR (1996) Comparison of methods for predicting deficient network performance. J Water Resour Plann Manag 122(3):214-217

Kalungi P, Tanyimboh TT (2003) Redundancy model for water distribution systems. Reliab Eng Syst Saf 82(3):275-286

Kougias IP, Theodossiou NP (2013) Multi-objective pump scheduling optimization using harmony search algorithm and polyphonic HSA. Water Resour Manag 27(5):1249-1261

Kovalenko Y, Gorev NB, Kodzhespirova IF, Prokhorov E et al (2014) Convergence of a hydraulic solver with pressure-dependent demands. Water Resour Manag 28:1013-1031

Kurek W, Ostfeld A (2013) Multi-objective optimization of water quality, pumps operation, and storage sizing of water distribution systems. J Env Manag 115:189-197

Murphy LJ, Dandy GC, Simpson AR (1994) Optimum design and operation of pumped water distribution systems. Proc Hydraul Civil Eng Conf, Institution of Engineers, Brisbane, Australia, 149-155

Prasad TD (2010) Design of pumped water distribution networks with storage. J Water Resour Plann Manag 136(1):129-132

Prasad TD, Tanyimboh TT (2008) Entropy based design of "Anytown" water distribution network. Proc $10^{\text {th }}$ Ann Water Distrib Syst Anal Conf, ASCE/EWRI, Kruger National Park, South Africa, 450-461. doi: 10. $1061 / 41024(340) 39$

Rossman LA (2002) EPANET 2 User's Manual, Water Supply and Water Resources Division, National Risk Management Research Laboratory, Cincinnati, OH45268 
Saleh HSA, Tanyimboh TT (2013) Coupled topology and pipe size optimization of water distribution systems. Water Resour Manag 27(14):4795-4814. doi:10.1007/s11269-013-0439-4

Saleh SHA, Tanyimboh TT (2014) Optimal design of water distribution systems based on entropy and topology. Water Resour Manag 28(11):3555-3575

Saleh SHA, Tanyimboh TT (2016) Multi-directional maximum-entropy approach to the evolutionary design optimization of water distribution systems. Water Resour Manag 30(6):1885-1901. doi:10.1007/s11269016-1253-6

Seyoum AG, Tanyimboh TT (2014) Pressure dependent network water quality modelling. J Water Manag 167(6):342-355. doi:10.1680/wama.12.00118

Siew C, Tanyimboh TT (2010a) Pressure-dependent EPANET extension: extended period simulation. $12^{\text {th }}$ Inte Conf Water Distrib Syst Anal, ASCE/EWRI, Tucson, Arizona, USA, 85-95. doi: 10.1061/41203(425)10

Siew C, Tanyimboh TT (2010b) Penalty-free multi-objective evolutionary optimization of water distribution systems. 12 $2^{\text {th }}$ Int Conf Water Distrib Syst Anal, ASCE/EWRI, Tucson, Arizona, USA, 764-770. doi: 10. $1061 / 41203(425) 71$

Siew C, Tanyimboh T (2012a) Penalty-free feasibility boundary-convergent multi-objective evolutionary algorithm for the optimization of water distribution systems. Water Resour Manag 26(15):4485-4507

Siew C, Tanyimboh TT (2012b) Pressure-dependent EPANET extension. Water Resour Manag 26(6):1477-1498

Siew C, Tanyimboh T, Seyoum A (2014) Assessment of penalty-free multi-objective evolutionary optimization approach for the design and rehabilitation of water distribution systems. Water Resour Manag 28(2):373-389

Spiliotis M, Tsakiris G (2011) Water distribution system analysis: Newton-Raphson method revisited. J Hydraul Eng ASCE 137(8):852-855

Spiliotis M, Tsakiris G (2012) Water distribution network analysis under fuzzy demands. Civ Eng Environ Syst 29(2):107-122

Tanyimboh T, Templeman A (2000) A quantified assessment of the relationship between the reliability and entropy of water distribution systems. Eng Optim 33(2):179-199

Tanyimboh TT, Templeman AB (2010) Seamless pressure-deficient water distribution system model. J Water Manag 163(8):389-396. doi:10.1680/wama.900013

Tanyimboh TT, Tahar B, Templeman AB (2003) Pressure-driven modelling of water distribution systems. Water Sci Technol - Water Supply 3(1-2):255-261

Tanyimboh TT, Tietavainen MT, Saleh SHA (2011) Reliability assessment of water distribution systems with statistical entropy and other surrogate measures. Water Sci Technol - Water Supply 11(4):437-443

Todini E (2000) Looped water distribution networks design using a resilience index based heuristic approach. Urban Water 2(3):115-122

Vamvakeridou-Lyroudia LS, Walters GA, Savic DA (2005) Fuzzy multiobjective optimization of water distribution networks. J Water Resour Plann Manag 131(6):467-476

Walski TM (1987) Discussion of multi-objective optimization of water distribution networks. Civ Eng Syst 4(1): 215-217

Walters GA, Halhal D, Savic D, Ouazar D (1999) Improved design of “Anytown” distribution network using structured messy genetic algorithms. Urban Water 1(1):23-38

WHO (World Health Organization) (2011) Guidelines for drinking-water quality. WHO, Geneva 